\title{
THE NUMBER OF NURSES AND MIDWIVES PER 1000 INHABITANTS INFLUENCES LIFE EXPECTANCY: A RETROSPECTIVE ANALYSIS BASED ON DATA FROM 46 COUNTRIES
}

BOŻENA CZARKOWSKA-PĄCZEK ${ }^{1}$, MAŁGORZATA DAWIDOWSKA ${ }^{2}$, and LENA SERAFIN ${ }^{1}$

${ }^{1}$ Medical University of Warsaw, Warsaw, Poland

Department of Clinical Nursing

${ }^{2}$ Medical University of Maria Skłodowska-Curie, Warsaw, Poland

Institute of Medical Science

\begin{abstract}
Objectives: Increased life expectancy results in greater challenges posed to healthcare. Concurrently, a shortage of healthcare workforce, including nurses, has been observed. Thus, an urgent need exists to implement improvements in healthcare services based on sufficient evidence. The aim of the study was to evaluate the influence of the relative number of nurses/midwives on life expectancy, and the influence of selected economic variables: gross domestic product (GDP), health expenditure as a percentage of GDP, and health expenditure per capita, on this number. Material and Methods: A retrospective analysis based on data from 46 countries was performed. Correlations between the relative number of nurses/midwives and life expectancy as well as economic variables were evaluated. To trace the differences between the countries with different relative numbers of nurses/ midwives, the countries were divided into groups as follows - group 1: $<5$ nurses and midwives/1000 nurses inhabitants, group 2: 5-10 nurses and midwives/1000 inhabitants, and group 3: $>10$ nurses and midwives/1000 inhabitants. Results: Correlations were found between the relative number of nurses/midwives and life expectancy $(\mathrm{p}<0.001, \mathrm{r}=0.68)$, and economic variables $(\mathrm{p}<0.001, \mathrm{r}=0.82 ; \mathrm{p}<0.001, \mathrm{r}=0.62$, and $\mathrm{p}<0.001, \mathrm{r}=0.8$, respectively). Life expectancy was higher in group 3 vs. groups 1 and 2 ( $p<0.001$ and $p=0.036$, respectively), and in group 2 vs. group 1 ( $p=0.006$ ). Economic variables were higher in group 3 vs. group $1(p<0.001$ for all) and group $2(p=0.016, p=0.025, p=0.022$, respectively), and in group 2 vs. group $1(p=002, p=0.024, p=0.002$, respectively). Conclusions: The relative number of nurses/midwives correlates with life expectancy and relies on the country's income and level of healthcare system financing. Int J Occup Med Environ Health. 2021;34(4):505-12
\end{abstract}

Key words:

nursing, life expectancy, healthcare, economic status, healthcare workforce, relative number of nurses/midwifes

\section{INTRODUCTION}

According to the universal health coverage (UHC) established by the World Health Organization (WHO) all people of all ages should achieve better health and wellbeing in the field of disease prevention, health promotion, and treatment for communicable and non-communicable diseases [1]. Thus, an urgent need exists to implement improvements in healthcare services based on sufficient evidence. Life expectancy is the result of many factors, including healthcare system regulations and resources,

Received: August 10, 2020. Accepted: November 12, 2020.

Corresponding author: Bożena Czarkowska-Pączek, Medical University of Warsaw, Department of Clinical Nursing, Ciołka 27, 01-445 Warsaw, Poland (e-mail: bozena.czarkowska-paczek@wum.edu.pl). 
the socio-economic status, disease prevention approaches, lifestyle and health financing systems, education, government and private health expenditure, access to safe water, nutritional outcomes, the geographical status and urbanization, the mortality rates of infants, children and adults, and the birth rate, and mother and child care $[2,3]$.

Life expectancy has increased over the last several years, especially in high-income countries. Due to variations in the pace of economic growth, the countries with the highest life expectancy have changed several times. One of the results of this phenomenon is a simultaneous increase in the size and proportion of the elderly population, namely those who need care the most [2,4]. In addition, the elderly are accompanied by multimorbidity, which also increases the need for advanced care and medical treatment $[5,6]$. This situation requires careful planning of health and social services. Currently, a shortage has been observed in healthcare workforce, namely among physicians and nurses [7]. It has been also demonstrated that there is an association between daily work load/nurse/day, and patient safety [8]. Many potential solutions have been established to reduce this shortage, including not only an increase in the number of nurses and midwives, but also increasing their roles and skills, and broadening their competencies in the healthcare system. Optimizing the roles of nurses could contribute to the progressive realization of the UHC objective [9].

Presuming their leading roles in UHC, Global Strategic Directions for Strengthening Nursing and Midwifery 2016-2020 (SDNM) was launched in 2016 by the WHO. This is a policy guidance providing a framework with which to adapt, develop, implement, and evaluate interventions leading to an increased and improved role of nurses and midwives in the healthcare system at the country level [10]. However, though 35 of the Government Chief Nursing and Midwifery Officers or their representatives have reported that $74 \%$ of the 22 country-level interventions included in SDNM are either completed or "in progress" [9], there are still some issues restricting the development of this oc- cupational group. These restrictions include the shortage and maldistribution resulting in overstrain, low pay, a lack of legal regulations enhancing the professional and scientific development, or workplace bullying [11,12]. These challenges and restrictions are still present in many countries, with under-evaluation and a persistently low social status of the nursing profession.

The aim of the present study was to prove the importance of nurses and midwives in the healthcare system. To this end, the authors evaluated the influence of the relative number nurses/midwives on life expectancy and the influence of selected economic indicators on this number.

\section{MATERIAL AND METHODS}

A retrospective analysis was performed based on data from 46 countries. Data regarding the relative number of nurses/midwives, life expectancy, and 3 indicators of the economic status: gross domestic product (GDP) per capita, health expenditure as a percentage of GDP, and health expenditure per capita, regarding 2015-2016, were obtained from the reports of the World Bank, Eurostat, and the Organization for Economic Cooperation and Development (OECD) [13-16].

Initially, 211 countries were selected for the analysis, but after evaluating the timeliness and completeness of the reports, the analysis included 46 countries. The authors analyzed 26 countries with different economic statuses in Europe: Austria (AT), Belgium (BE), Czech Republic (CZ), Denmark (DK), Estonia (EE), Finland (FI), France (FR), Germany (DE), Great Britain (GB), Holland (NL), Hungary (HU), Iceland (IS), Italy (IT), Ireland (IE), Lithuania (LT), Luxembourg (LU), Montenegro (ME), Norway (NO), Poland (PL), Russia (RU), Slovak Republic (SK), Slovenia (SI), Spain (ES), Switzerland $(\mathrm{CH})$, Sweden (SE), and Turkey (TR). They also analyzed 4 countries in the North and South Americas (Canada [CA], Mexico [MX], Paraguay [PY], and the USA [US]), 10 countries in Asia (China [CN], India [IN], 
Indonesia [ID], Iran [IR], Israel [IL], Japan [JP], Kazakhstan [KZ], Malaysia [MY], Thailand [TH], and Vietnam [VN]), 4 countries in Africa (Gabon [GA], Kenya [KE], Tunisia [TN], and Zimbabwe [ZW]), as well as Australia (AU), and New Zealand (NZ).

The impact of the relative number of nurses/midwives on life expectancy was evaluated in the countries included in this analysis. The authors also evaluated the impact of selected economic variables on the relative number of nurses/midwives in the analyzed countries.

To evaluate the differences between the countries in the context of the relative number of nurses/midwives regarding the selected indicators, e.g., life expectancy and economic variables, the investigated group of countries was divided into 3 separate subgroups: those with $<5$ nurses and midwives/1000 inhabitants (group 1: PY, ZW, ID, VN, KE, IN, TH, CN, TR, MX, TN, GA, and MY), those with 5-10 nurses and midwives/1000 inhabitants (group 2: IL, ES, PL, ME, SK, EE, IT, HU, LT, CZ, GB, KZ, RU, SI, NL, CA, and US), and those with $>10$ nurses and midwives $/ 1000$ inhabitants (group 3: FR, BE, NZ, SE, JP, IE, AT, LU, $\mathrm{AU}, \mathrm{IR}, \mathrm{DE}, \mathrm{FI}, \mathrm{IS}, \mathrm{DK}, \mathrm{NO}$, and $\mathrm{CH}$ ). In every group, the mean and standard deviation, as well as the median and range were calculated for the selected indicators.

\section{Statistical analysis}

All statistical calculations were performed in the R statistical package (ver. 3.4.3). The Kruskal-Wallis test was used to compare variables between the groups with post-hoc Dunn's test and Holm's correction for multiple comparisons. To detect significant relationships between the variables, Pearson's methods were applied. In all analyses, the results were considered significant when $p<0.05$.

\section{RESULTS}

The descriptive statistics of the analyzed indicators stratified according to the relative number of nurses/midwives are presented in Table 1. Dunn's test with Holm's correction for multiple comparisons revealed that life expectancy was higher in group 3 vs. groups 1 and $2(p<0.001$ and $p=0.036$, respectively), and in group 2 vs. group $1(p=0.006)$. Economic variables were higher in group 3 vs. group 1 ( $p<0.001$ for all) and group 2 (GDP per capita, $\mathrm{p}=0.016$; health expenditure [a percentage of GDP], $\mathrm{p}=0.025$, and health expenditure per capita, $\mathrm{p}=0.022$ ), and in group 2 vs. group 1 (GDP per capita, $\mathrm{p}=0.002$; health expenditure [a percentage of GDP], $\mathrm{p}=0.024$, and health expenditure per capita, $\mathrm{p}=0.002$ ).

The relationships between the relative number of nurses/ midwives and life expectancy at birth in the whole population (2016), GDP per capita (2016), the current health expenditure as a percentage of GDP (2015), and the current health expenditure per capita (2015) in the analyzed countries are shown in Figure $1 \mathrm{a}-\mathrm{d}$, respectively.

Pearson's test revealed strong correlations between the relative number of nurses/midwives and life expectancy $(p<0.001, r=0.68)$. Strong correlations were also identified between the relative number of nurses/midwives and GDP per capita (Pearson's test, $\mathrm{p}<0.001, \mathrm{r}=0.82$ ), health expenditure as a percentage of GDP (Pearson's test, $\mathrm{p}<0.001, \mathrm{r}=0.62$ ), and health expenditure per capita (Pearson's test, $\mathrm{p}<0.001, \mathrm{r}=0.8$ ).

\section{DISCUSSION}

As it was already mentioned, life expectancy is the result of many factors, including healthcare system regulations [2]. These results show that nurses and midwives play an important role. The increasing demand for healthcare worldwide and its decreased quality have created the urgent need to implement quality improvements, but in many cases the interventions that are implemented are not based on sufficient empirical evidence [17]. Therefore, measurements of quality have become the critical activities leading to improved healthcare delivery and financing. In 2005, the Robert Wood Johnson Foundation established the Interdisciplinary Nursing Quality Research Initiative. 


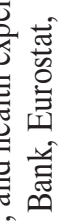

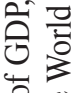

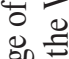

혼

을 은

\%

害要

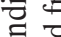

핸.

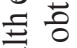

홀

si

촐

ะ

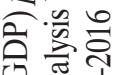

일

몽

응.

항

政

政

응

寻

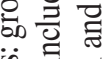

$\dot{s}$.

记

要品

23

․․․․․

흘

:

용

害要

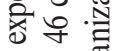

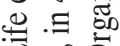

$\because 3$

$\div$ 응

产这

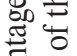

흥 항

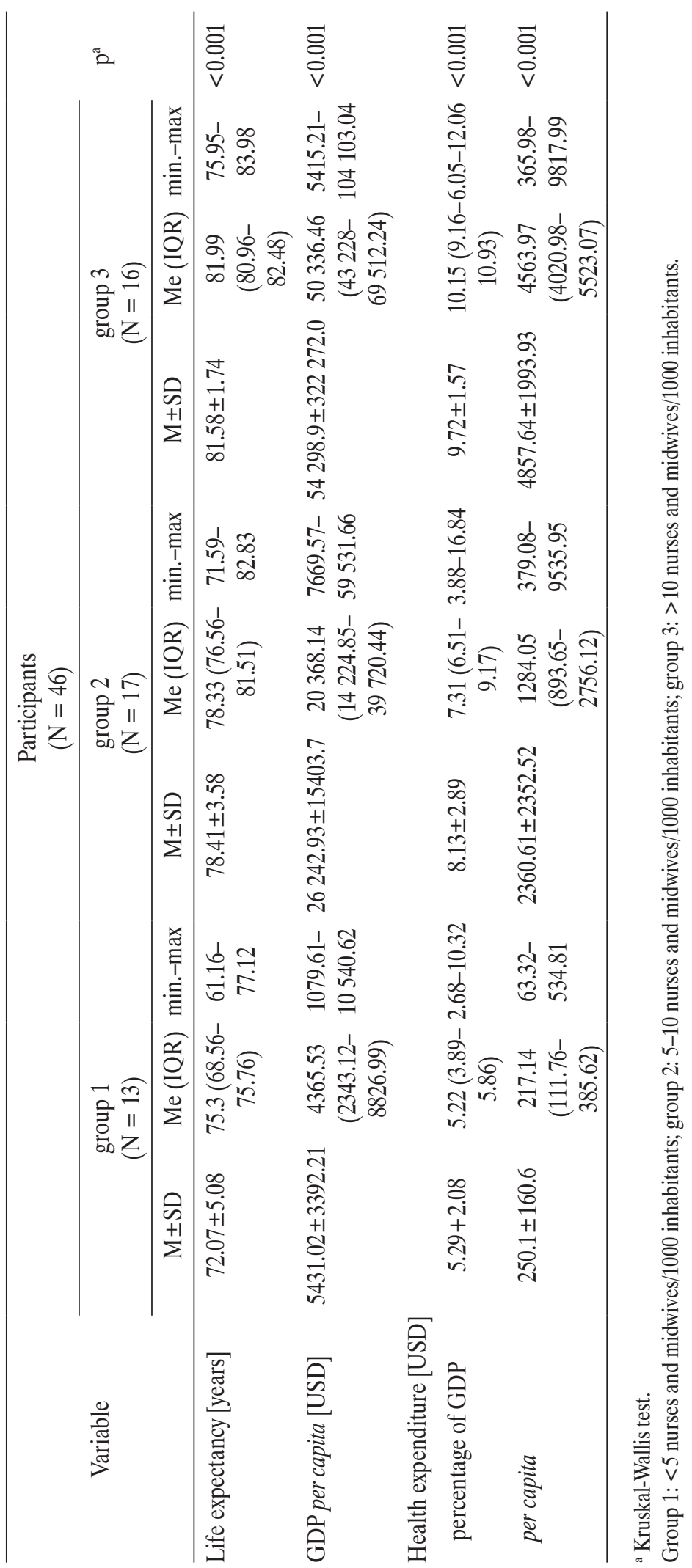



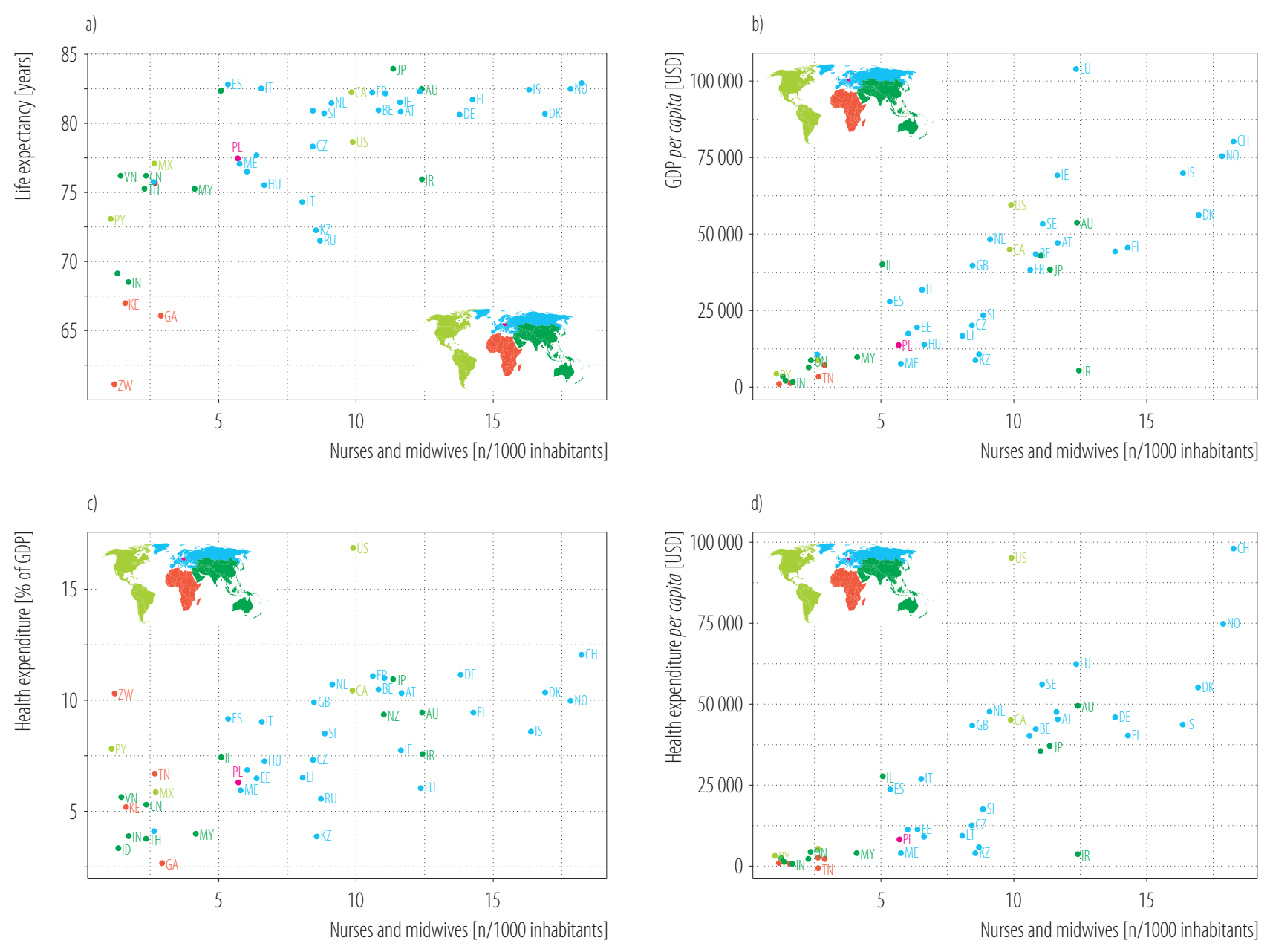

Africa (Gabon - GA, Kenya - KE, Tunisia - TN, and Zimbabwe - ZW), America (Canada - CA, Mexico - MX, Paraguay - PY, the USA - US), Asia (China - CN, India - IN, Indonesia - ID, Iran - IR, Israel - IL, Japan - JP, Kazakhstan - KZ, Malaysia - MY, Thailand - TH, and Vietnam - VN), Australia - AU and New Zealand - NZ, Europe (Austria - AT, Belgium - BE, Czech Republic - CZ, Denmark - DK, Estonia - EE, Finland - FI, France - FR, Germany - DE, Great Britain - GB, Holland - NL, Hungary - HU, Iceland - IS, Ireland - IE, Italy - IT, Lithuania - LT, Luxembourg - LU, Montenegro - ME, Norway - NO, Poland - PL, Russia - RU, Slovak Republic - SK, Slovenia - SI, Spain - ES, Sweden - SE, Switzerland - CH, and Turkey - TR).

Figure 1. The relationships between the number of nurses and midwives/1000 inhabitants (2015) and a) life expectancy at birth in the whole population (2016), b) gross domestic product (GDP) per capita (2016), c) current health expenditure as a percentage of GDP (2015), and d) current health expenditure per capita (2015)

The purpose of this program was to produce evidence linking nursing and the quality of healthcare [18]. The outcomes of the scientific papers that followed clearly indicate that the nursing profession possesses many strengths that highlight the importance of nurses and midwives in multidisciplinary teams and their basic role in improving the healthcare system.
The appropriate and optimal number of nurses and midwives/1000 inhabitants is a crucial factor. Much evidence indicates that appropriate nurse staffing and patient-tonurse ratios in healthcare facilities are associated with lower mortality rates [19-21]. The results of this study are in line with the need to provide evidence of the role of nurses and midwives in the healthcare system. The authors dem- 
onstrated that life expectancy is influenced by the number of nurses and midwives/1000 inhabitants and is higher in the countries where this number is high. However, there are countries where this proportion is not sustained. For example, Iran has 1.55 nurses and midwives/1000 inhabitants and its life expectancy is 75.98 years. Similarly, Spain and Italy have 5.32 and 5.72 nurses and midwives/1000 inhabitants, respectively, and their life expectancy is 82.83 and 82.54 years, respectively. In contrast, Belarus, Kazakhstan, and Russia have 11.42, 8.54, and 8.68 nurses and midwives/1000 inhabitants, respectively, and their life expectancy is $73.8,72.3$, and 71.59 years, respectively. This discrepancy could result from many factors, including the level of nursing/midwife education and competency, the organization of the healthcare system, the level of individual income, and health behaviors, among others.

In addition, life expectancy depends on the country's income [22-24]. Rudolf Virchow [25] was the first to point out the relationship between poverty and the health status of the society. It has also been shown that life expectancy is influenced by the country's income, and that the number of nurses and midwives/1000 inhabitants is higher in the countries with higher income and a higher level of financing for the healthcare system. In many countries, there is an increasing share of healthcare services provided by nurses, mostly by advanced practice registered nurses. The number of such nurses has increased rapidly, especially in the USA. The training time is shorter compared to the physician's training, and there are fewer constrains resulting from the capacity of medical schools and institutional restrictions [26,27].

There are many benefits flowing from an increased role of nurses in healthcare services. First, it fills the gap between the demands for healthcare services and the system's ability to meet these expectations. The quality of care provided by nurses, especially in the field of primary care in community settings, is similar to that provided by physicians, or could be even better in regard to patient outcomes. Nurses achieve a higher level of patient satisfaction, consultation length is longer, and the frequency of attended return visits is slightly higher for nurses than for doctors [28,29]. The cost of primary care provided by nurses is also significantly lower than the cost of physician-provided care [30]. Nurses, in particular, want more respect, a good collaboration from doctors, clearly defined roles, adequate training, resources, and supervision. These needs are not always met [31].

\section{Limitations}

This study has some limitations. First, the position of the nurses, their competencies, and roles, as well as the organization of the nursing field, vary in different countries, and these differences were not considered here. Second, the authors only analyzed countries with complete data reported in relevant and commonly accessible sources. Third, life expectancy depends on many variables, while this study only considered the relative number of nurses/ midwives and selected economic variables.

\section{CONCLUSIONS}

This is the first study to assess the influence of the relative number of nurses/midwifes on life expectancy based on objective data. The study provided evidence regarding the relative number of nurses/midwifes in terms of life expectancy. The results indicate that nurses are very important in the healthcare system, and their relevant contribution should be considered by policy makers, especially as the number of nurses in the country relies on the country's income and the level of financing for the healthcare system. Strengthening the role of nurses and midwives could contribute to reducing global healthcare disparities.

\section{REFERENCES}

1. World Health Organization [Internet]. Geneva: The Organization; 2017 [cited 2019 Jul 25]. Together on the road to universal health coverage. A call to action. Available from: https://www. who.int/universal_health_coverage/road-to-uhc/en/. 
2. Kontis V, Bennett JE, Mathers CD, Li G, Foreman K, Ezzati M. Future life expectancy in 35 industrialised countries: projection with Bayesian model ensemble. Lancet. 2017;389 (10076):1323-35, https://doi.org/10.1016/S0140-6736(16)323 $81-9$.

3. Ranabhat CL, Atkinson J, Park M-B, Kim C-B, Jakovljevic M. The Influence of Universal Health Coverage on Life Expectancy at Birth (LEAB) and Healthy Life Expectancy (HALE): A Multi-Country Cross-Sectional Study. Front Pharmacol. 2018;9:960, https://doi.org/10.3389/fphar.2018.00960.

4. Cohen SA. A review of demographic and infrastructural factors and potential solutions to the physician and nursing shortage predicted to impact the growing US elderly population. J Public Health Manag Pract. 2009;15(4):352-62, https://doi. org/10.1097/PHH.0b013e31819d817d.

5. Rocca WA, Boyd CM, Grossardt BR, Bobo WV, Finney Rutten LJ, Roger VL, et al. Prevalence of multimorbidity in geographically defined American population: patterns by age, sex, and race/ethnicity. Mayo Clin Proc. 2014;89(10):1336-49, https://doi.org/10.1016/j.mayocp.2014.07.010.

6. Salive ME. Multimorbidity in older adults. Epidemiol Rev. 2013;35:75-83, https://doi.org/10.1093/epirev/mxs009.

7. World Health Organization [Internet]. Geneva: The Organization; 2016 [cited 2019 Jul 25]. Global strategy on human resources for health: workforce 2030. Available from: https://apps.who.int/iris/bitstream/handle/10665/250368/978 9241511131-eng.pdf.

8. Fagerstrom L, Kinnunen M, Saarela J. Nursing work load, patient safety incidence and mottality: an observational study from Finland. BMJ Open. 2018;8(4):e016367, https:// doi.org/10.1136/bmjopen-2017-016367.

9. Ajuebor O, McCarthy C, Li Y, Al-Blooshi SM, Makhanya N, Cometto G. Are the global strategic directions for strengthening nursing and midwifery 2016-2020 being implemented in countries? Findings from a cross-sectional analysis. Human Res Heath. 2019;17(1):54, https://doi.org/10.1186/s12960-019-0392-2.

10. World Health Organization [Internet]. Geneva: The Organization; 2016 [cited 2019 Jul 25]. Global Strategic Directions for Strengthening Nursing and Midwifery 2016-2020. Available from: https://www.who.int/hrh/nursing_midwifery/global-strategic-midwifery2016-2020.pdf.

11. Coomber B, Barriball KL. Impact of job satisfaction components on intent to leave and turnover for hospital-based nurses: a review of the research literature. Int J Nurs Stud. 2007;44(2):297-314.

12. Giorgi G, Mancuso S, Castiello D'Antonio A, Mucci N, Cupelli V, Arcangeli G. Bullying among nurses and its relationship with burnout and organizational climate. Int J Nurs Pract. 2016;22(2):160-8, https://doi.org/10.1111/ijn.12376.

13. World Bank Open Data [Internet]. The Organization; 2018 [cited 2018 Dec 18]. Available from: https://data.worldbank.org.

14. Eurostat Statistics Database [Internet]. The Organization; 2018 [cited 2018 Dec 18]. Available from: https://ec.europa. eu/eurostat/data/database.

15. OECD [Internet]. The Organization; 2017 [cited 2018 Dec 19]. Health at Glance. OECD Indicators 2017. Available from: https://www.health.gov.il/publicationsfiles/health ataglance2017.pdf

16. World Health Organization [Internet]. Geneva: The Organization; 2018 [cited 2018 Dec 18]. WHO European Health For All Database. Available from: https://gateway.euro.who. int/en/datasets/european-health-for-all-database/.

17. Flynn R, Scott SD, Rotter T, Hartfield D. The potential for nurses to contribute to and lead improvement science in health care. J Adv Nurs. 2017;73(1):97-107, https://doi. org/10.1111/jan.13164.

18. Naylor MD, Volpe EM, Lustig A, Kelley HJ, Melichar L, Pauly MV. Linkages between nursing and he quality of patients care. Med Care. 2013;51(4 Suppl 2):S6-14, https://doi. org/10.1097/MLR.0b013e3182894848.

19. Kim Y, Kim J, Shin SA. Relationship between the legal nurse staffing standard and patient survival after perioperative cardiac arrest: A cross-sectional analysis of Korean administrative data. Int J Nurs Stud. 2019;89:104-11, https:// doi.org/10.1016/j.ijnurstu.2018.09.012. 
20. McHugh MD, Rochman MF, Sloane DM, Berg RA, Mancini ME, Nadkarni VM, et al. American Heart Association's Get With The Guidelines-Resuscitation Investigators. Better nurse staffing and nurse work environments associated with increased survival of in-hospital cardiac arrest patients. Med Care. 2016;54(1): 74-80, https://doi.org/10.1097/MLR.0000000000000456.

21. Kelly DM, Kutney-Lee A, McHugh MD, Sloane DM, Aiken LH. Impact of critical care nursing on 30-day mortality of mechanically ventilated older adults. Crit Care Med. 2014;42(5):1089-95, https://doi.org/10.1097/CCM.00000000 00000127.

22. Chetty R, Stepner M, Abraham S, Lin S, Scuderi B, Turner N, et al. The Association Between Income and Life Expectancy in the United States, 2001-2014. JAMA. 2016;315(16):1750-66, https://doi.org/10.1001/jama.2016.4226. Erratum in: JAMA. 2017;317:90.

23. Lee H, Kim S, DeMarco R, Lin S, Scuderi B, Turner N, et al. Recognized global disparities in health and health transitions in the 21st century: what can nurse do? Appl Nurs Res. 2015;28(1):60-5, https://doi.org/10.1016/j.apnr.2014.09.004.

24. Gapminder [Internet]. Stockholm: The Foundation; 2011 [cited 2019 Jul 27]. Available from: https://www.gapminder. org/answers/how-does-income-relate-to-life-expectancy/.

25. Virchow RC. Report on the typhus epidemic in Upper Silesia. Am J Public Health. 2006;96(12):2102-5, https://doi.org/ 10.2105/ajph.96.12.2102.
26. Bodenheimer TS, Smith MD. Primary care: proposed solutions to the physician shortage without training more physicians. Health Aff (Millwood). 2013;32(11):1881-6, https:// doi.org/10.1377/hlthaff.2013.0234.

27. Auerbach DI, Staiger DO, Buerhaus PI. Growing Ranks of Advanced Practice Clinicians - Implications for the Physician Workforce. N Engl J Med. 2018;378(25):2358-60, https://doi.org/10.1056/NEJMp1801869.

28. Laurant M, van der Biezen M, Wijers N, Watananirun K, Kontopantelis E, van Vught AJ. Nurses as substitutes for doctors in primary care. Cochrane Database Syst Rev. 2018;7(7):CD001271, https://doi.org/10.1002/14651858.CD001271.pub3.

29. Tothova V, Bartlova S, Sedova L, Treslova M, Chloubova I, Proskova E. The nurse' role in preventive care in the field of community nursing. Neuro Endocrinol Lett. 2014;35 Suppl 1: 26-33.

30. Perloff J, Des Roches CM, Buerhaus P. Comparing the cost of care provided to Medicare beneficiaries assigned to primary care nurse practitioners and physicians. Health Serv Res. 2016;51(4):1407-23, https://doi.org/10.1111/1475-6773.12425.

31. Karimi-Shahanjarini A, Shakibazadeh E, Rashidian A, Hajimiri K, Glenton C, Noyes J, et al. Barriers and facilitators to the implementation of doctor-nurse substitution strategies in primary care: a qualitative evidence synthesis. Cochrane Database Syst Rev. 2019;4(4)CD010412, https://doi. org/10.1002/14651858.CD010412.pub2.

This work is available in Open Access model and licensed under a Creative Commons Attribution-NonCommercial 3.0 Poland License - http://creativecommons.org/ licenses/by-nc/3.0/pl/deed.en. 